\title{
Cache Me If You Can: Reflections on Geocaching from Junior/Intermediate Teacher Candidates
}

\author{
John L. Vitale, Michael McCabe, Stephen Tedesco, Taunya Wideman-Johnston \\ Nipissing University
}

\begin{abstract}
Junior/Intermediate teacher candidates were introduced to a geocaching activity (a high-tech scavenger hunt using hand-held GPS devices) that addressed the two principal strands from the Social Studies curriculum in Ontario, Canada, namely; (a) Heritage and Citizenship and (b) Canada and World Connections as well as specific expectations from the Mathematics, Health and Physical Education, Language and Literacy, and Science and Technology curriculae. Through a mixed-methods research design, surveys and reflective journal entries were analyzed to determine the attitudes, perspectives, and opinions of teacher candidates. Results have determined that the vast majority of participants found the geocaching experience vastly efficacious and highly valuable. Specifically, participants responded favourably to six principal categories, namely; (a) fun and enjoyment, (b) discovery learning, (c) space and place learning, (d) future application considerations, (e) cross-curricular integration ideas, and (f) social skills application.
\end{abstract}

Key words: technology, social studies, geocaching, integrated learning, inclusive education.

\section{Introduction}

Geocaching is a worldwide treasure hunting game utilizing GPS (Global Positioning Systems) technology. The fundamental idea of geocaching is to find outdoor hidden containers, named geocaches and ultimately share the experience online. Although originally geared toward outdoor enthusiasts, geocaching has now crossed over into the educational arena, particularly in the Social Studies curriculum. Research has stated: "Social studies teachers use geocaching to encourage students to research and visit important local historical landmarks, learn longitude and latitude, and connect content learned in the classroom to actual places and people.” [14]. Moreover, hand-held GPS devices helped students gain intuition about the abstract relationship between maps and the physical space they represent for students as young as the third grade [24].

"Geocaching is of interest because it is comprised of both location-based elements and on-line elements. Understanding the diverse relationship between in-situ and on-line behaviours is an important area of interest" [22]. Moreover, the incorporation and application of GPS technology can animate and improve the overall standing and reputation of Social Studies, especially considering that Social Studies is considered by many to be a dull and boring subject [5]; [11]. In sum, geocaching breathes life into dry, theoretical concepts that have plagued the Social Studies curriculum for decades.

\section{Curriculum Integration Via the Social Studies Classroom}

There is ample support for the integration of many subjects into individual lessons and units [26]. Not surprisingly, geocaching offers a plethora of cross-curricular integration opportunities. In Literacy, for example, students can gain knowledge in story sequencing and increase vocabulary [29]. In Science, students can explore geological formations and observe their natural surroundings such as plant and animal life [10]. In Mathematics, teachers employ geocaching to help their students solve logic problems, use and recall key concepts, and study and supply distances and angles [13] From the perspective of healthy-active living (Physical Education), geocaching offers tremendous opportunities to exercise for all levels of fitness, including walking, jogging, bicycling, and even canoeing [19]. Moreover, geocaching in groups can even increase social bonds and relationships among students [15], including virtual social bonds [22].

\section{Methodology and Theoretical Framework}

The subjects for this study consist of 61 Junior/Intermediate teacher candidates in their fourth year of the concurrent Bachelor of Education Program at Nipissing University in Brantford, Ontario, Canada. These teacher candidates were introduced to geocaching via an interactive scavenger hunt through the local downtown core of Brantford, Ontario. All participants were provided with an in class introduction to the theoretical aspects of geocaching including its application to their future classrooms and the wider world. This included direct links between geocaching and the various Ontario curriculae mentioned above with special attention given to the two fundamental 
strands of Heritage and Citizenship and World Connections in Social Studies. In addition, students had the opportunity to explore existing websites dedicated to promoting geocaching. This was followed by an outdoors introduction to the basic operational procedures of the hand-held GPS devices, which included several practice locations commonly referred to as waypoints.

Once participants completed the geocaching course, they were asked to reflect on their overall experience through two modes of representation, namely; (a) responding to a survey, and (b) writing a reflective journal entry. This study, therefore, is theoretically rooted in a mixed methods approach to inquiry [6] - the surveys are quantitative and the journal reflections are qualitative. It has been argued that using multiple methods is a "valuable approach that does not merely duplicate data but also offers complementary insights and understandings that may be difficult to access through reliance on a single method of data collection“ [9].

Survey questions have been a chief method of collecting data since the mid-19th century dating back to the work of English scholar Sir Francis Galton. Heavily rooted in the quantitative paradigm, surveys provide an overarching and broad viewpoint from the sample size, statistically revealing major trends and developments of participants [16]. For this study, five close-ended questions (anonymously answered) were used, and intended to be a starting point to elicit participant attitudes and perspectives toward geocaching as both a learning activity and pedagogical tool. Close-ended questions are used in the majority of surveys and are modest and straightforward platform to elicit responses from participants [3]. Lastly, surveys allow for easier coding, categorization, and statistical interpretation (please refer to Appendix I for the five questions used in this study).

Closed-ended questions, however, can result in suggesting responses that participants may not normally come up with on their own. This inherent disadvantage will be addressed primarily by the qualitative data generated via reflective journals written by the participants. In addition, there was an open forum for additional comments on the surveys, which some participants opted to use.

Reflective journals provide deep personal insight into each individual participant and are an exceptional method of deducing what has been learned and why. As teacher educators, we are firm believers in reflective practice. Reflection can help professionals develop their practice [25]. In addition, "teaching will remain at best uninformed, and at worst ineffective, prejudiced and constraining" without critical reflection [12]. . One of the most effective ways to engage in meaningful reflective practice is through journal writing. Specifically, journals allow the writer to break habitual ways of thinking, develop reflective judgment and metacognition, facilitate self-exploration and personal growth, and acquire solutions [17]; [18]. Research that best summarizes the impact that journal writing has on learning states: "The journal holds experiences as a puzzle frame holds its pieces. The writer begins to recognize the pieces that fit together and, like the detective, sees the picture evolve” [30]. Journal writing, therefore, is a very useful tool for all professionals and particularly for emerging pre-service teachers. This study borrows from the theoretical perspectives of phenomenology, in that we are interested in the subjective experiences of junior/intermediate teacher candidates and the integration of GPS technology in their future pedagogic practice. Also, "Phenomenology is a school of thought that emphasizes a focus on people's subjective experiences and interpretations of the world. That is, the phenomenologist wants to understand how the world appears to others" [28]. Moreover, reflective practice is the primary process of any phenomenological inquiry [20].

All surveys were completed immediately after the terminus of the geocaching experience in order to avoid memory deficit. Answers to the survey questions were based on a five-point Likert scale. This scale was selected for its familiarity and simplistic nature [1] with "one" equating to a negative association and "five" a positive association. An average numerical response out of five (with 5 being the most favourable) was calculated for each of the items in the survey (with the exception of question 5). Question five asked the participants to select one subject area out of seven that would be best served by geocaching (see Appendix I).

Participants had one week to complete their reflective journals. One week was deemed long enough to internally process the geocaching experience, and short enough to accurately describe their thoughts and feelings. On average, journal reflections were one and a half pages in length approximately four hundred words. A pseudonym for each participant in this study was used to ensure confidentiality.

\section{Results}

As constructed in the survey, the six principal categories with regards to their geocaching experience included (a) fun and enjoyment, (b) discovery learning, (c) space and place learning, (d) future application considerations, (e) cross-curricular integration ideas, and (f) social skills application. The participants reported exceedingly positive and affirmative aspects of the overall geocaching experience in all six categories. 


\subsection{Fun and Enjoyment}

In terms of the overall enjoyment, an overwhelming $93 \%$ of the participants found the geocaching assignment enjoyable, rating the experience either a four or five out of five on question one (rate your overall enjoyment of the geocaching experience). Moreover, this significantly high level on enjoyment was clearly evident in many of the journal reflections. Linda, for example, stated, "Geocaching was the most fun Social Studies assignment I have ever completed. I had never geocached before and I was not quite sure what to expect. However, as soon as my group started our route, I was hooked. It was like a version of scavenger hunt."

In addition, Jenna not only had fun, but rated this assignment as the best in her entire university experience: "The assignment was probably the most fun I have ever had in a university class”. Similarly, Caitlyn stated: "I had a blast doing the geocaching assignment. I honestly cannot remember the last time I had so much fun in a class and learned so much while doing it”. In terms of learning, Caitlyn's remarks are also consistent with the second question of the survey, where $88 \%$ of the participants scored a four or five out of five in terms of finding educational value in the geocaching experience. Interestingly, Candy rated this assignment as not only her favourite in a university setting, but in all her previous educational experiences: "This activity was by far one of my favourite activities ever in all my schooling. Tora's comments are worth noting, "The geocaching assignment is one of my favourite assignments I have ever done! It was very hands on, interesting, fun and engaging. It sparked my interest in a variety of ways. I cannot say that I really disliked anything about this assignment."

A few participants also made additional comments (anonymously) on the survey to support this category. Such comments included: "A lot of fun”, "Really enjoyed this assignment”, “Awesome! Had a great time", and "Fantastic and sweet assignment”.

\subsection{Discovery Learning}

Discovery learning has been considered an important part of the learning process since 1961 [2]. Many of the participants in this study found the act of discovery and exploration a major part of the geocaching experience. For example, Katrina stated, "After doing today's geocaching assignment I was left humbled and intrigued to explore Brantford more. Through this assignment I was able to explore the downtown core, a place I travel to daily, but had no idea that some of the monuments and views were located right below my feet."
Similarly, Sara stated, "I had a lot of fun figuring out the clues and seeing parts of Brantford that I didn't really know about. Although I have been to some of the spots that we were to find, I have never actually looked at them closely to see what they really represented for Brantford, and it was good to see that. It was also good to get out of the classroom and experience Brantford in a different way; one that was not just solely based on the school campus." Moreover, Amanda reflected on the historical landmarks in the city of Brantford that she was exposed to as a result of the geocaching, "One of the reasons I enjoyed geocaching is that a cache can take me somewhere that I would probably miss otherwise. For instance, on our walk out in Brantford I noticed historical and cultural landmarks filled with interesting evidence of early settlers in the area."

Similarly, Milena also made reference to the variety of things she discovered within the city of Brantford, and wished this had happened earlier in her university career, "I very much enjoyed participating in the geocaching experience. I found that this really opened my eyes to all that Brantford has to offer. I wish that I had done something like this earlier in my university career. This way I would have a better idea of how to navigate my way around this city."

Holly's reflections are also quite noteworthy, as she also makes reference to the process of learning: "Our geocaching experience was not about getting the right answers or a competition to get to the end, but it was about exploring and discovering. It was the journey we took to get our answers which was important”. Perhaps Kayla's short and sweet remarks, however, best summarize the high level of discovery found in the geocaching experience, "There is a great deal of mystery and surprise that accompanies this task." In sum, we found the outcome of this category very surprising, as the participants were in their final year of study and already had over three years of experience living in the city of Brantford.

\subsection{Geocaching as a Tool for Teaching the Concepts of Space and Place}

The concepts of "space" and "place” are key components of Social Studies, and many participants made reference to this aspect of the curriculum, particularly the application of latitude and longitude. For example, Janine stated, "Last semester I took a physical geography class and at times I found longitude and latitude difficult to understand. This activity being hands on allowed me to understand these concepts in everyday life and not just on maps. It also made the concepts of using latitude and longitude a lot more fun. It was interesting to see it being used in my everyday life to places that I had previously been.” 
Loretta, however, comments on learning more about the city in which she has been attending university for well over three years, "As a commuter I have not had the opportunity to fully explore Brantford. I really enjoyed learning about Brantford from this assignment. Prior to this assignment I did not know that there was a skate park, a walkway over the Grand River or stairs and a park to get to the Grand River.

Micheline actually used the terms "spaces" and "places" in her reflection, "Geocaching would apply to Social Studies, because you can make the course specific to the unit you are discussing, such as spaces, places, people, nature, landscapes, and many more. It is a great tool for students to learn their community and discover on their own or in small groups."

The category of "spaces and places" can also be supported from the responses to question four of the survey -- did the geocaching route make you more aware of the history and geography of the city of Brantford? An overwhelming 91\% answered with a four or five out of five on this particular question.

\subsection{Cross Curricular Integration}

Many of the participants found geocaching to be an exceptional vehicle for cross-curricular integration. Kathy, for example, stated: "I thought it was incredible how this project fit into so many subjects in the curriculum: Physical Education, Science, Social Studies, Math and Language Arts.” Jamina has similar sentiments in her reflection, but also ties in the relationship that geocaching has to Gardner's Multiple Intelligence Theory, “This assignment is brilliant as it not only introduces new technology to students but it also forces them to be active (Physical Education), to work with the concept of distance and puzzles (Mathematics) to learn about their community and latitude and longitude (Social Studies). Furthermore, this activity addressed six of Howard Gardner's eight intelligences: linguistic, logical-mathematical, spatial, bodily-kinesthetic, interpersonal and naturalist."

In addition, Jolene was very thorough in her comments on the cross-curricular features of geocaching, "The geocaching assignment in this course was amazing. It was a fun and competitive way to teach important aspects of Social Studies. Geocaching is great because it incorporates so many different subject areas. The geocaching assignment incorporates the use of math skills, history about the local community, using mapping skills, simple concepts of geography, as well as daily physical activity. Because geocaching reaches so many different curriculum strands it would be perfect for any grade to complete.”
Further support for the cross-curricular integration of geocaching can be found in question five of the survey, which asks: Which subject curriculum would be most appropriate for geocaching? Responses were varied with Geography being the highest at 25\%, followed by Math and Physical Education, at 20\% each. History also scored well (15\%), with Science at $10 \%$, and the Arts, Language Arts, and French making up the remaining $10 \%$.

\subsection{Inclusive Education: Social Benefits, Communication Skills and Cooperative Learning}

Although geocaching can be an individual activity, it can also be a very entertaining and educational social activity for two or more people. All of the participants in this study completed the geocaching activity in groups of two or more, and many of them commented on its social aspect, particularly the cooperative skills required. Kalinda, for example, reflected on the opportunity to work and interact with people that she never worked with before: "This assignment was also fun because I got to work with some people I have never talked to before and we got along really well and all had an equal role in the assignment." Carli echoed similar thoughts: "I enjoyed working in a team. I do not know my teammate but we were still able to cooperate, problem-solve, and get to know one another." Lana reflected on the learning experience of working with a partner, "As we were working with our partner to reach an ultimate goal, we had to make decisions together along the way. If one of us was wrong, we were both wrong, and this activity allowed us to develop skills for cooperative learning.

Moreover, Terri had a similar reflection, “Aside from the curricular benefits the geocaching activity was ideal to work on communication skills between members of the group. Everyone had a great attitude in helping one another out, expressing opinions or ideas and lending assistance in regards to understanding the material. It was great to develop the team-work skills necessary to complete such an activity successfully.”

Anonymous comments on the survey also promoted the category of "Social Benefits, Communication Skills \& Cooperative Learning”, including: "It required a lot of teamwork to answer the questions and navigate the GPS unit", "Our group had a great time together", and "It was a great walk through the city sharing ideas and conversation with my classmates.”

As the qualitative data has illustrated, the geocaching experience is very much associated with the concept of inclusive education, which "promotes social cohesion, belonging, active participation in learning, a complete school experience, and positive 
interactions with peers and others in the school community” (2012, New Brunswick Department of Education).

\section{Future Application}

As researchers, it was important for us to know whether or not the participants of this study would incorporate geocaching in their future teaching. In fact, $82 \%$ of participants scored either a four or five on question three of the questionnaire (rate the applicability of geocaching to your future teaching career). Moreover, many of the reflections were affirmative in this regard. Jeanette, for example, stated: "I could definitely see myself using this in my future classroom. As a teacher you can make it suitable for your class and add your own special touches to make it your own." Similarly, Helen acknowledged that she will be using geocaching in her classroom: "Overall geocaching is a fabulous activity to implement into any curriculum and relate it to subject areas across the board. I will definitely be implementing it into my future classroom, as I believe it is an amazing tool." Moreover, Cora's reflections indicate that she too will definitely use geocaching in her future classroom: "I would certainly use geocaching in my classroom, particularly for grades 4 and up. I think that if enough time and effort is put into planning and organization, geocaching can be extremely beneficial for students, particularly in achieving the principal objectives of inclusive education, which has become a key initiative for many Boards of education.

\section{Conclusion}

Results of this study have determined that geocaching is a valuable, highly interactive, and technologically oriented approach to teaching a variety of subjects at the Junior/Intermediate level. Teacher candidates thoroughly enjoyed their geocaching experience and were overwhelmingly in support of using this technology in their future teaching practice. Moreover, participants found the overall experience imbued with educational value, which is, in essence, tied into all of the six categories addressed in this study. Evidence of this phenomenon can be found in question three (rate the overall educational value of the geocaching experience), where an overwhelming 96\% answered a four or five out of five. Of these $96 \%$ of participants, $88 \%$ scored a five out of five. Educational value, therefore, was perceived as paramount to the overall geocaching experience. Additional comments anonymously provided on the surveys also support this notion, including: "I learned a lot of new things today", and "I was exposed to a new world of learning today”.
As both researchers and teacher educators, we are continuing to explore and investigate all that geocaching has to offer with our teaching candidates. Plans for the next academic term include having teacher candidates conceptualize, plan, and design their own geocaching routes for peer-to-peer application. In addition, we are anxious to take this project to the next level. We are currently requesting further funding for more sophisticated handheld GPS that have the capability of running the Wherigo player, which allows users to create interactive location-aware adventure games that bridge physical and digital spaces, and transform the city space into a virtual game board.

Nipissing Brantford has also initiated a partnership with the "David Suzuki Foundation". Currently, this partnership includes the development of environmental education curriculum initiatives. It is our hope that this partnership can be enhanced through proactive projects (e.g., Geocaching, Wherigo m-Learning activities) that emphasize links between the environment and teacher education, demonstrating the various ways in which teachers can impact their students and schools' participation. It is also our hope that schools will consider incorporating geocaching as a method of practically employing inclusive education principles. Moreover, we are also interested in partnering with the people of the Six Nations, a local Aboriginal community, o work with educators in designing learning activities that actively promote, support, and politicize the principles of native education through technological learning. Ultimately, our goal is to politicize the incorporation of geocaching within the elementary and secondary school curriculum across Canada and beyond, particularly from the perspective of inclusive education.

\section{Appendix 1: Geocaching Questionnaire}

(1) Rate your overall enjoyment of the geocaching experience.

$\begin{array}{lcccc}1 & 2 & 3 & 4 & 5 \\ \text { Lowest } & & & & \text { Highest }\end{array}$

(2) Rate the overall educational value of the geocaching experience.

$\begin{array}{lcccc}1 & 2 & 3 & 4 & 5 \\ \text { Lowest } & & & & \text { Highest }\end{array}$

(3) Rate the applicability of geocaching to your future teaching career.

$\begin{array}{lllcc}1 & 2 & 3 & 4 & 5 \\ \text { Lowest } & & & & \text { Highest }\end{array}$


(4) Did the geocaching route make you more aware of the history and geography of your surrounding (the city of Brantford)?

$\begin{array}{lrlcc}1 & 2 & 3 & 4 & 5 \\ \text { Lowest } & & & & \text { Highest }\end{array}$

(5) What area of the curriculum would be most appropriate for geocaching? (circle one only)

Math Language Arts French

Social Studies Science $\quad$ Phys. Ed.

The Arts

Please provide us with some additional comments.

\section{References}

[1] Blazey, Mark (2008). Insights to performance excellence 2008: An inside look at the 2008 baldrige award criteria. Milwaukee, WI: Quality Press.

[2] Bruner, J. S. (1961). "The act of discovery". Harvard Educational Review 31 (1): 21-32.

[3] Bradburn N, Sudman S, \& Wansink B. (2004). Asking questions: The definitive guide to questionnaire design. San Francisco: Jossey-Bass.

[4] Bullock, P., Park, V., \& Snow, J. (2002). Redefining interdisciplinary curriculum: A journey of collaboration and change in secondary teacher education. Interchange, 33, 159-182.

[5] Chiodo, John J. and Jeffery Byford (2004). Do they really dislike social studies? A study of middle school and high school students. Journal of Social Studies Research, Spring 2004.

[6] Creswell, J. (2009). Research design qualitative, quantitative, and mixed methods Approaches, (3rd Ed.).Thousand Oaks, California: Sage.

[7] Cresswell, J. \& Clark, V. (2007). Designing and conducting mixed methods research. Thousand Oaks, California: Sage.

[8] Daly, J., Kellehear, A. \& Gliksman, M. (1997). The public health researcher: A methodological approach. Melbourne, Australia: Oxford University Press.

[9] Darbyshire, P., MacDougall, C. and Schiller, W. (2005). Multiple methods in qualitative research with children: more insight or just more? Qualitative Research. 5(4): 417-436

[10] Geological Society of America (2006). Guidelines for submittal. Retrieved April, 2010, from http://www.geosociety.org/earthcache/guidelines.htm
[11] Heafner, T. (2004). Using technology to motivate students to learn social studies. Contemporary Issues in Technology and Teacher Education [Online serial], 4(1).

[12] Hillier, Yvonne (2005). Reflective teaching in further and adult education. 2nd Edition. New York: Continuum.

[13] Larry, L. M. (2004). Hide and seek: GPS and geocaching in the classroom. Learning and Leading with Technology, 31(6), 14-18. Retrieved March, 2010, from ERIC Online Database (ERIC Document Number EJ695752):

http://www.eric.ed.gov/ERICDocs/data/ericdocs2sql/conte nt_storage_01/0000019b/80/2a/16/e0.pdf

[14] Matherson, L., V. Wright, C. Inman \& E. Wilson (2008). Get Up, Get Out With Geocaching: Engaging Technology for the Social Studies Classroom. Social Studies Research and Practice. Volum3, No. 3, pp. 80-85.

[15] McFerrin, K., Weber, R., Carlsen, R., \& Anna, D. (Eds.), Proceedings of Society for Information Technology \& Teacher Education International Conference 2008 (pp. 5340-5342). Chesapeake, VA: AACE. Retrieved April, 2012 from http://www.editlib.org/p/28129.

[16] Mellenbergh, G.J. (2008). Chapter 10: Tests and Questionnaires: Construction and administration. In H.J. Adèr \& G.J. Mellenbergh (Eds.) (with contributions by D.J. Hand), Advising on Research Methods: A consultant's companion (pp. 211--236). Huizen, The Netherlands: Johannes van Kessel Publishing.

[17] Mitchell, C. and Coltrinari, H. (2001). Journal Writing for Teachers and Students. In The Craft of Teaching Adults. 3rd edition, edited by T. Barer-Stein and $\mathrm{M}$. Kompf, pp. 21-38. Toronto: Irwin Publishing.

[18] Moon, J. A. (1999). Learning journals: A handbook for academics, students, and professional development. London: Kogan Page.

[19] Moss (2010). Fitness: Geocaching Makes Walking Fun for PE Classes. Dick Moss, Editor, Physical Education Update Retrieved April, 2010 at http://www.physicaleducationupdate.com/public/293.cfm

[20] Mostert, Willemina (2002). Phenomenology: Discovering new meanings of pedagogy within the lived experience. A paper presented at the Association for Active Educational Researchers. Brisbane, Australia: December 1 - 5, 2002.

[21] New Brunswick Department of Education (2012). "Inclusive Education." Retrieved June, 2012 from http://www.gnb.ca/0000/publications/Definition\%20of\%20 Inclusion.pdf

[22] O’Hara, K. (2008). Understanding geocaching practices and motivations Conference on Human Factors in Computing Systems. Proceeding of the twenty-sixth annual SIGCHI conference on Human factors in computing systems table of contents. Florence, Italy, SESSION: On the Move table of contents. Pp 1177-1186. 
[23] Rice, P., \& Ezzy, D. (1999). Qualitative research methods: A health focus. Melbourne, Australia: Oxford University Press.

[24] Rosenberg, L. (2004). The Design of a Constructivist Learning Experience that uses GPS Technology. In L. Cantoni \& C. McLoughlin (Eds.), Proceedings of World Conference on Educational Multimedia, Hypermedia and Telecommunications. 2004 (pp. 4837-4841). Chesapeake, VA: AACE. Retrieved April, 2010 from http://www.editlib.org/p/11763.

[25] Schön, D. A. (1991). The Reflective Practitioner: How Professionals Think, Arena, London.

[26] Spalding, E. (2002). Of organelles and octagons: What do preservice secondary teachers learn from interdisciplinary teaching? Teacher and Teacher Education, 18, 699-714.

[27] Trimpe, T. (2005). Mapping the refuge. Retrieved April, 2010, from http://sciencespot.net/Media/GPSMappingRefuge.pdf

[28] Trochim, William (2006). "Research methods knowledge base." Retrieved March, 2010 at http://www.socialresearchmethods.net/kb/qualapp.php

[29] White-Taylor, J. \& Donellon, P. (2008). Geocaching in Education. In K. McFerrin et al. (Eds.), Proceedings of Society for Information Technology \& Teacher Education International Conference 2008 (pp. 5340-5342). Chesapeake, VA: AACE.

[30] Williamson, A. (1997). Reflection in Adult Learning with Particular Reference to Learning-in-Action. Australian Journal of Adult and Community Education 37, no. 2: 93-99. 